\title{
Achieving the Framework Convention on Tobacco Control's potential by investing in national capacity
}

\author{
H Wipfli, F Stillman, S Tamplin, V Luiza da Costa e Silva, D Yach, J Samet
}

Tobacco Control 2004;13:433-437. doi: 10.1136/tc.2003.006106

May 2003 marked a critical achievement in efforts to stem the global tobacco epidemic, as the member states of the World Health Organization unanimously endorsed the Framework Convention on Tobacco Control (FCTC). However, the adoption of the FCTC signifies only the end of the beginning of effective global action to control tobacco. Over the next several years the utility of the FCTC process and the treaty itself will be tested as individual countries seek to ratify and implement the treaty's obligations. Significant barriers to the treaty's long term success exist in many countries. It is crucial that the international tobacco control community now refocuses its efforts on national capacity building and ensures that individual countries have the knowledge, tools, data, people, and organisations needed to implement the convention and develop sustained tobacco control programmes. This paper provides a model of national tobacco control capacity and offers a prioritised agenda for action.

See end of article for authors' affiliations

Correspondence to: Dr Frances A Stillman, Institute for Global Tobacco Control, Johns Hopkins Bloomberg School of Public Health, 615 North Wolfe Street, Room W 6027, Baltimore, MD 21205, USA:

fstillma@jhsph.edu

Received

14 September 2003

Accepted 21 May 2004
$\mathrm{T}$ he adoption of the Framework Convention on Tobacco Control (FCTC) in 2003 marked a critical achievement in efforts to stem the global tobacco epidemic. The FCTC negotiations raised the political profile of tobacco as a global public health problem, improved awareness among policy makers, and resulted in an agreed upon agenda for action. However, the adoption of the FCTC signifies only the end of the beginning of effective global action to control tobacco. Over the next several years, the utility of the FCTC process and the treaty itself will be tested as individual countries seek to ratify and implement the treaty's obligations.

Significant barriers to the treaty's long term success remain in many countries, especially those in the middle and low income range. These include:

- a lack of locally relevant evidence and data gathering/surveillance infrastructure in many countries

- inadequate expertise in relation to some areas of research, health systems development, and policy formation and implementation

- insufficient leadership and networking

- lack of national foci for tobacco control, including both governmental and nongovernmental entities
- little investment in funding for research and programmes directed at the control of tobacco use and tobacco attributable disease.

In the long run, the FCTC will only be successful in countries that have strong and durable capacity in tobacco control. Countries need the capability to implement the treaty's obligations and to respond to the unintended consequences of increased national and international regulation of tobacco products. The FCTC process and recent national tobacco control developments in many countries have had a significant impact on global tobacco control capacity. Tobacco control advocates worldwide must now build on the political momentum generated throughout the FCTC process and ensure that individual countries have the knowledge, tools, data, people, and organisations needed to implement the convention and develop sustainable tobacco control programmes.

This paper provides a conceptual model of national tobacco control capacity and offers a prioritised agenda for action. However, models alone will not overcome the necessary prerequisite for developing greater tobacco control capacity-funding. Therefore, the paper also aims to identify avenues for procuring greater investment in national tobacco control activities and maximising the scarce resources available.

\section{DEFINING NATIONAL TOBACCO CONTROL CAPACITY}

National tobacco control capacity refers to the indigenous capability of countries to develop and deliver comprehensive, multi-sectoral action so as to provide the appropriate prevention and control strategies to reduce tobacco use in their countries. This capability is reflected in three essential and overlapping components in the national environment: (1) expertise and leadership; (2) infrastructure; and (3) empirical evidence (fig 1). National capacity building, therefore, refers to programmes aimed at enhancing one of these three elements. In practice, national capacity building is often reflected through the development of a national plan of action, designation of a lead government agency for tobacco control, training of tobacco control professionals, and research initiatives aimed at

Abbreviations: COPD, chronic obstructive pulmonary disease; FCA, Framework Convention Alliance; FCTC, Framework Convention on Tobacco Control; GTRN, Global Tobacco Research Network; GYTS, Global Youth Tobacco Survey; NGO, non-governmental organisation; PAHO, Pan American Health Organization; WHO, World Health Organization 


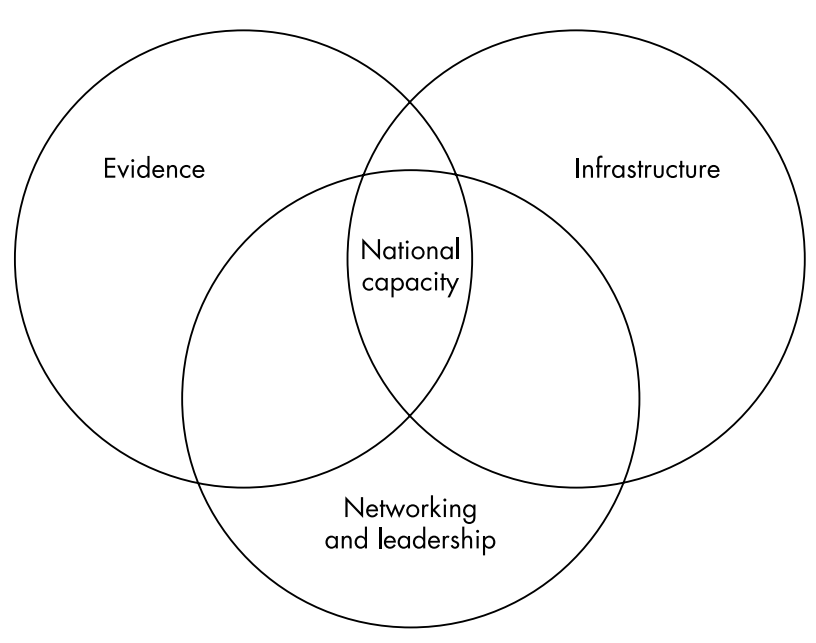

Figure 1 Components of national capacity.

providing evidence to legitimate the programmes or policies that must be instituted. ${ }^{1}$

\section{Empirical evidence}

Empirical evidence comes from data collected both incountry and abroad on the health and economic consequences of tobacco use and the effects of specific tobacco control policies and other regulatory approaches. It also refers to surveillance data on industry activities. These data need to be available in multiple forms to assure accessibility to researchers, policymakers, advocates, and the general public.

FCTC Article 20 (Research, surveillance, monitoring and exchange of information) outlines the minimum amount of evidence needed in every country. ${ }^{2}$ In order to fulfil the treaty's fundamental research and surveillance obligations, countries need:

- basic health statistics, including cause specific mortality data

- estimates of the burden of disease caused by smoking

- data on tobacco prevalence and use

- standardise measures and methods to monitor tobacco control policy and programme progress

- industry tracking, including cost of cigarettes, advertising and promotion, brand stretching, and sponsorship. ${ }^{2}$

Local evidence needs to be used in combination with, and build linkages to, the voluminous external evidence already gathered by expert groups and governments throughout the world. While the development of comprehensive tobacco control policies should not be delayed until a full suite of national evidence is available, tobacco control research in different national settings must continue, including research on the epidemiology of tobacco related disease. Although evidence confirms that tobacco causes disease in humans wherever it is consumed, recent studies from low and middle income countries show that the burden of disease may largely depend on other national risk factors. For example, for less developed countries, tuberculosis and other diseases may be far greater contributors to disease burden than lung cancer, chronic obstructive pulmonary disease (COPD), and coronary heart disease. ${ }^{3}$ Although many tobacco control measures have universal applicability, how and why they should be implemented differs greatly. In India, for example, bidis and smokeless tobacco are currently taxed at very low levels to "protect the poor". Further increases in tobacco taxes may lead consumers to switch to bidis if bidi taxes are kept low. If taxes are to become part of a control strategy, serious political effort based on solid economic data gathered by both the World Bank and Indian economists will be needed. ${ }^{5}$

Countries will also need to monitor their national capacity development as well as assess the programmes and policies that are implemented. By developing standardised measures to assess national capacity and strength of tobacco control, cross country comparisons could be made to track progress. ${ }^{67}$ Tracking the countervailing force, the tobacco industry efforts, is another important area for research and surveillance. ${ }^{6}$

\section{Infrastructure}

To support the development and implementation of comprehensive tobacco control programmes, countries need an inplace effective, supportive infrastructure. Infrastructure refers to the availability of the broad skills, tools, and systems needed to conduct policy relevant research, communicate evidence, frame collective debate, propose policy options, implement policy recommendations, and deliver treatment. This includes a capable health care delivery system, which includes treatment for tobacco dependence. National tobacco control infrastructure should also include a governmental focal point for tobacco, preferably an office dedicated to tobacco control, and national programs to support tobacco control training.

FCTC Article 21 (Cooperation in the scientific, technical, and legal fields, and provision of related expertise) provides for infrastructure development in middle and low income countries. $^{2}$ The provisions include commitments to: support the establishment of training and educational programmes; provide materials, equipment and supplies; and provide technical, scientific, and legal assistance. Continued region and country specific mutual learning opportunities, the implementation of associated surveillance mechanisms, and the development of technical resources will be crucial in fulfilling these obligations and improving global tobacco control infrastructure.

The FCTC process contributed significantly to enhancing tobacco control infrastructure in many countries. Multiple countries established formal inter-ministerial committees to prepare for the FCTC negotiations. These committees gave different ministries (health, finance, customs, and agriculture, for example) the opportunity, often for the first time, to discuss and address the domestic burden of tobacco. ${ }^{8}$ At the negotiating sessions, countless reports, briefing papers, and fact sheets were distributed and technical seminars were held on a broad range of tobacco control issues amounting to what has been called "the best university of global tobacco control." ${ }^{\prime 9}$

Multiple new tools have also been and are being developed to increase global tobacco control infrastructure. These include the economic toolkit developed by the World Bank, the WHO Recommendations for Smoking Cessation, and the World Bank's review of successful national case studies. ${ }^{10-12}$ In addition, numerous online tobacco control training resources are currently under development. Many of these tools and resources are now widely accessible on the internet to tobacco control advocates working at the local and national level.

\section{Networking and leadership}

To the extent possible, tobacco control research should be policy relevant and tobacco control policy should be evidence based. Policymakers, advocates, and others need to collaborate in the identification of country research needs and develop a strategic plan for tobacco control that reflects short term action and long term thinking and planning. National tobacco control action plans, as well as country specific 
strategies for the ratification and implementation of the FCTC, are urgently needed in many countries.

In order to develop and implement coherent national tobacco control strategies, countries need networks of individuals and organisations that share information and expertise and work in a coordinated fashion. Tobacco control is highly multidisciplinary, requiring engagement of a wide range of individuals in tobacco control activities, including researchers, public health professionals, economists, lawyers, advocates, political scientists, business people, and politicians. National tobacco control coalitions can facilitate communication between the different participants involved so that they work synergistically toward common objectives. Throughout the FCTC negotiations, the Framework Convention Alliance (FCA) (a network of individual nongovernmental organisations (NGOs), organisations, and existing coalitions/alliances working at national, regional, and international levels to support the development of a strong FCTC) demonstrated the effectiveness of NGOs working together in encouraging policymakers to remain committed to the overarching public health objectives of tobacco control.

Importantly, every country also needs visible tobacco control champions. Although there is no magic formula for getting effective tobacco control legislation passed, past successes have largely depended on policy entrepreneursboth individuals and groups-willing to champion the issue; of politicians committed to public health and to placing tobacco control on the policy agenda; of researchers who have published and publicised compelling national or international data; and of national, regional, and international political, social, economic, and policy environments that supported action. ${ }^{13}$ Champions can come from a wide variety of disciplines and interests. They need to have a demonstrated interest in tobacco control, access to their own networks, and influence in their areas of focus. ${ }^{13}$ Moreover, they should be capable of mobilising public opinion and knowledgeable about how to support policy change in culturally appropriate ways. The adoption of the FCTC demands a renewal of national tobacco control leadership. Currently there are very few leadership training courses and few global opportunities to show leadership. One exception is the FCA's new tobacco control advocacy leadership workshops being carried out in each WHO region. Efforts to identify new, motivated individuals and keep them engaged demand a systematic approach to health leadership development and a long term commitment and investment from tobacco control partners with resources and experience.

\section{NATIONAL CAPACITY PRIORITY SETTING}

Over the past few years, numerous organisations have developed prioritised agendas for global tobacco control activities. ${ }^{14}{ }^{15}$ The FCTC negotiations process was in itself a type of agenda setting exercise. The challenge is to take these existing agendas and identify which elements are most relevant in any given country. The national capacity framework offered in this paper provides a helpful structure for identifying national priorities. By separating tobacco control activities according to how they impact the national environment, tobacco control advocates can better prioritise interventions. For example, if tobacco control advocates determine that their country mainly lacks infrastructure, they may well wish to focus initially on those activities that are most likely to contribute to capacity growth in that area.

In order to adequately evaluate the different elements of national tobacco control capacity, tobacco control partners incountry and internationally must be able to identify what has been done already in the country, who is active in the country at the moment, what gaps need to be filled, and who may be interested in funding certain types of new tobacco control initiatives. This requires systematic reviews of past tobacco control initiatives and improved communication between the national and international tobacco control communities. In the short term, virtual communication through networks and email exchanges, such as those already existing within Globalink, offer the most effective way of providing these needs.

Generally speaking, there are a few critical activities that should be carried out in each of the three elements of national capacity in order to facilitate progress in tobacco control globally (table 1). In terms of evidence, international collaboration could help to fill several of the evidence gaps that exist in many low and middle income countries. These include the collection of data and associated analyses in relation to the prevention of tobacco use among women; the development of more effective cessation and prevention strategies; and the analysis of tax policies in support of research and tobacco control initiatives. Evidence can be conducted relatively easily and at reduced costs through multi-country protocols. The Global Youth Tobacco Survey (GYTS) provides one example of how common templates can be used to ensure the compatibility of data for international comparison and evaluation. ${ }^{16}$ Other current multi-country initiatives include the Pan American Health Organization (PAHO) and Johns Hopkins Bloomberg School of Public Health's joint study of exposure to secondhand smoke in eight Central and South America countries, and a six country study of cigarette content and cotinine levels among smokers of different ethnic backgrounds. ${ }^{17}{ }^{18}$

In terms of infrastructure, every country needs a government office dedicated to tobacco control in order to facilitate the implementation of legislation in accordance with FCTC obligations. Virtual networks can also help to provide infrastructure at low cost. Currently, a Global Tobacco Research Network (GTRN) is being developed to delineate tobacco control research related opportunities and resources available to low income countries; optimise the sharing and use of available tobacco control research resources; identify research gaps; and facilitate the conduct of research that helps resolve priority issues. ${ }^{19}$ A global legislative support network could also be developed to provide countries with assistance in adapting laws to comply with FCTC obligations, mobilise legal mentoring and support through law schools, and facilitate the exchange of information regarding tobacco industry activities and influence. Both networks could offer an issue specific expert/reference service to provide timely support for policy initiatives that arise suddenly in developing countries.

Networking and leadership can be rapidly improved through development of national coalitions of governmental and non-governmental tobacco control organisations. New national and international training programs and leadership opportunities are also needed.

\section{PROCURRING INVESTMENT FOR CAPACITY DEVELOPMENT}

The available resources to address tobacco control are insufficient, especially in the context of a highly aggressive and well funded industry that is focused on maintaining and expanding its global market. Currently there are multiple new international efforts to fund tobacco control and there are a number of international organisations whose mission is relevant to tobacco control but who have not yet been enlisted in the global tobacco control effort.

A recent resource related development in international tobacco control research is the new grants programme from the National Institutes of Health, Fogarty International Center, entitled "International tobacco and health research 
Table 1 Research priorities to build national capacity

\begin{tabular}{|c|c|c|c|}
\hline \multicolumn{2}{|c|}{ Component } & \multirow{2}{*}{$\begin{array}{l}\text { Priority } \\
\text { Effects of smoking on diseases in less } \\
\text { developed countries, e.g. tuberculosis }\end{array}$} & \multirow{2}{*}{$\begin{array}{l}\text { Rational } \\
\text { For less developed countries, tuberculosis and other diseases may be far } \\
\text { greater contributors to disease burden than lung cancer, COPD, and } \\
\text { coronary heart disease }\end{array}$} \\
\hline$\bullet$ & Evidence & & \\
\hline & & Economics of tobacco control & $\begin{array}{l}\text { Need to understand macro-economic factors in low, middle, and high } \\
\text { income countries especially related to how higher taxes will reduce use } \\
\text { among youth and poor }\end{array}$ \\
\hline & & Regulation of tobacco products & $\begin{array}{l}\text { Research to assess consequences of regulation on initiation, cessation, and } \\
\text { health effects is needed in order to modify the regulatory process on an } \\
\text { ongoing basis }\end{array}$ \\
\hline & & $\begin{array}{l}\text { Implementation, enforcement, and evaluation } \\
\text { of tobacco control policies }\end{array}$ & $\begin{array}{l}\text { Need to understand the cultural, social, and political factors that facilitate } \\
\text { or inhibit the adoption of tobacco control policies (e.g. smoke-free places, } \\
\text { advertising bans, and health warnings) as well as factors that lead to } \\
\text { enforcement of existing policies }\end{array}$ \\
\hline & & $\begin{array}{l}\text { Development of individual and population focused } \\
\text { interventions to promote cessation methods for } \\
\text { smokers in less developed countries }\end{array}$ & $\begin{array}{l}\text { Research on societal barriers to quitting as well as communication methods } \\
\text { suitable for different populations. Investigate different policy approaches to } \\
\text { encourage cessation }\end{array}$ \\
\hline & & $\begin{array}{l}\text { Interventions to prevent smoking initiation by women } \\
\text { and protect women and children from exposure to } \\
\text { secondhand smoke }\end{array}$ & $\begin{array}{l}\text { Women are a global target of the tobacco industry. Investigate approaches } \\
\text { that use family planning, hospital visits, and other venues to reach women } \\
\text { and vulnerable populations }\end{array}$ \\
\hline & & Interventions for health care professionals & $\begin{array}{l}\text { Need to encourage cessation among health care professionals as well as } \\
\text { improve their knowledge, motivation and skills to promote cessation }\end{array}$ \\
\hline \multirow[t]{3}{*}{$\bullet$} & Infrastructure & Creating coalitions of tobacco control partners & $\begin{array}{l}\text { Need to establish better linkages among tobacco control groups within } \\
\text { countries that include government agencies, research organisations and } \\
\text { NGOs so that efforts are more comprehensive and synergistic }\end{array}$ \\
\hline & & Development of tracking and surveillance systems & $\begin{array}{l}\text { Develop cost effect methods to monitor the tobacco epidemic as well as to } \\
\text { obtain data to evaluate progress to strengthen tobacco control policies and } \\
\text { programmes and assess compliance with FCTC. Surveillance of both } \\
\text { tobacco control activities and the tobacco industry activities is needed }\end{array}$ \\
\hline & & Interventions aimed at health care system & $\begin{array}{l}\text { Research on how to incorporate cessation within national health care } \\
\text { systems especially at the primary care level }\end{array}$ \\
\hline \multirow[t]{3}{*}{ - } & $\begin{array}{l}\text { Networking and } \\
\text { leadership }\end{array}$ & Creation of virtual networks & $\begin{array}{l}\text { Efficient knowledge transfer through networks such as the Global Tobacco } \\
\text { Research Network are cost effective and provide essential tobacco control } \\
\text { information to large numbers of researchers and advocates }\end{array}$ \\
\hline & & $\begin{array}{l}\text { Training to develop skills in advocacy, research, } \\
\text { policy and programme implementation and evaluation }\end{array}$ & $\begin{array}{l}\text { Efficient methods to train the next generation of tobacco control experts are } \\
\text { needed. These can include training centres and the use of distance } \\
\text { education and other web based methods to disseminate information }\end{array}$ \\
\hline & & Preparing new leaders for tobacco control & $\begin{array}{l}\text { Identify knowledge, skills and abilities required to assume leadership roles } \\
\text { in tobacco control as well as investigate new methods to provide training } \\
\text { and mentorship }\end{array}$ \\
\hline
\end{tabular}

and capacity building program for tobacco control research and training". ${ }^{20}$ The programme, directed at supporting transdisciplinary research and capacity building projects in low and/or middle income nations, is designed to promote international cooperation and linkages between investigators in high income nations pursuing research programmes on tobacco control, and scientists and institutions in low and/or middle income nations, where tobacco consumption is a current or anticipated public health urgency.

The Fogarty grants add to a variety of international research activities, such as: (1) Rockefeller and Thai Health Promotion Foundation's Trading Tobacco for Health Initiative in Southeast Asia; (2) The Open Society Institute's tobacco control initiative in Eastern Europe; (3) International activities of the Centers for Disease Control, US National Cancer Institute, and the American Cancer Society; (4) WHO's Tobacco Free Initiative; and (5) worldwide research funding from Canada's Institute for Research for International Tobacco Control. ${ }^{21}$ While there are a number of organisations interested in tobacco control, the overall investment to date has been modest and most recently numerous foundations and organisations have shifted their focus and removed or reduced their funding for tobacco control. So, it is important that efforts are made to maintain and increase the commitment of those organisations already involved in supporting tobacco control.

Numerous untapped opportunities remain for national tobacco control resource mobilisation, from private foundations such as the Wellcome Trust to large governmental resources such as the European Community (EC). Development agencies remain one of the largest potential sources for future resource mobilisation. Tobacco is rapidly being recognised as a development issue. There is a steep social class gradient for all forms of tobacco use, and in many low and middle income countries poor farmers are meeting extremely high demand for tobacco. ${ }^{5}$ Tobacco control research, population interventions, and tobacco diversification projects all need to be linked to rural development.

Some development agencies have already expressed their willingness to contribute to tobacco control. In February 2003, European Union Commissioners met in Brussels to discuss tobacco control and development policy. The Commission expressed its willingness to assist those countries that see tobacco control as a priority to develop the necessary expertise in the country to combat tobacco and to use the existing development cooperation instruments to build tobacco control capacity. ${ }^{22}$ The need for countries to prioritise tobacco control calls for continued national discussion and 


\section{What this paper adds}

Tobacco control advocates worldwide must build on the political momentum generated by the Framework Convention on Tobacco Control process and ensure that individual countries have the knowledge, tools, data, people, and organisational structures needed to implement the convention and develop sustainable tobacco control programmes. While numerous organisations have developed research and advocacy agendas for global tobacco control activities, these agendas have not provided a framework for individuals incountry to identify which national capacity building interventions are most appropriate in light of their domestic environment.

This paper offers a model and a discussion of the key components of national tobacco control capacity. An agenda and plan of action is presented that identifies research and interventions that require urgent attention in all regions. Finally, the paper points out important avenues for procuring greater investment in national tobacco control capacity activities as well as strategies to maximise scarce resources.

advocacy regarding the negative economic and social impacts of tobacco.

The development of national regulation could also bring sustained funding mechanisms for tobacco control programmes at the country level. ${ }^{1}$ Improved networking and collaboration has the potential to maximise the scarce resources available to national, state, and district health structures, while virtual networks and WHO Collaborating Centers offer specific avenues to long term sustained action in countries. Moreover, past tobacco control successes provide inspiring examples of individuals and organisations that have made a difference while working with minimal resources in hand. ${ }^{9}$

\section{CONCLUSION}

It is crucial to the control of the tobacco epidemic that the enthusiasm for the FCTC and the global tobacco control momentum generated by the FCTC negotiations not be lost. In the long run, the test of the FCTC's effectiveness will be whether or not it is successful in reducing the burden of disease caused by tobacco throughout the world. This can only happen if countries have the capacity needed to implement the treaty and develop their own vibrant tobacco control community capable of offering effective policy options and influencing the public consciousness.

The national capacity framework outlined in this paper provides a structure for developing a strategic plan for assisting developing countries with implementing the FCTC. The structure serves to remind those working in tobacco control that the development of sufficient national tobacco control capacity does not automatically follow from the attainment of short term policy objectives (for example, the adoption of the FCTC). Rather, it must be cooperatively built over time on a strong foundation of skills, tools, data, people, and organisations committed to supporting and sustaining tobacco control policy and practice.

External support agencies and technical partners must be willing to invest substantial time, monetary support, and other resources to build research and surveillance capacity in low and middle income countries. Short interventions, including invitations to one-off international conferences or training workshops, do not and can not be expected to result in true capacity development. The creation of virtual global networks are important resources that could lead to increased information exchange, technical assistance, and mentoring relationships that could help tobacco control researchers and policy advocates in developing countries maximise scare resources. Moreover, the networks could provide reliable indicators that would allow funding agencies, researchers, and advocates to identify how and where international investments in tobacco control research are being made; assess the effectiveness and usefulness of ongoing tobacco control initiatives; and encourage member states in their efforts to ratify and effectively implement the FCTC.

Now is the time for aggressive international investment in the development of national tobacco control capacity in developing countries facing the onslaught of the tobacco epidemic. Building on the success of the FCTC process, and the lessons learned through it, is the way to begin. Without this investment, the value of the time and resources put into the development of the FCTC will be greatly diminished.

\section{Authors' affiliations}

H Wipfli, F Stillman, S Tamplin, J Samet, Institute for Global Tobacco Control, Johns Hopkins School of Public Health, Baltimore, Maryland, USA

V Luiza da Costa e Silva, Tobacco Free Initiative, World Health Organization

D Yach, Yale School of Public Health

\section{REFERENCES}

1 World Health Organization. Tobacco control: strengthening national efforts. In: The World Health Report 2003 - shaping the future. Geneva: World Health Organization, 2003.

2 The WHO Framework Convention on Tobacco Control, World Health Assembly Resolution 56. 1, May 21, 2003.

3 Gajalakahmi V, Peto R, Kanaka TS, et al. Smoking and mortality from tuberculosis and other diseases in India. Lancet 2003;363:507-15.

4 Yach D. Partnering for better lung health: improving tobacco and tuberculosis control. International Journal Tuberculosis Lung Diseases 2000;4:693-7.

5 Yach D. Tobacco consumption in India. Journal Public Health Policy (in press).

6 Stillman FA, Hartman AM, Graubard BI, et al. The American stop smoking intervention study: conceptual framework and evaluation design. Evaluation Review 1999;23:259-80.

7 Stillman F, Hartman M, Graubard B, et al. Evaluation of the American stop smoking intervention study (ASSIST): a report of outcomes. J Nil Cancer Inst 2003;95:1681-93.

8 Wipfli H, Bettcher D, Subramaniam C, et al. Confronting the tobacco epidemic: emerging mechanisms of global governance. In: International cooperation and health. London: Oxford University Press, 2001:189-231.

9 Simpson B. Smoke Out! 2003. Johns Hopkins Public Health, Spring 2003:34.

10 World Bank, Economics of Tobacco Tool Kit, http://wwwl.worldbank.org/ tobacco/toolkit.asp September 5, 2003.

11 World Health Organization. Policy recommendations for smoking cessation and treatment of tobacco dependence. Geneva: WHO, 2003.

12 Waverley Brigden L, Beyer J. Tobacco control policy: strategies, successes, and setbacks. Washington DC: World Bank, 2003.

13 Subramaniam C. Advocacy for media change. NGO and Media Workshop. Geneva, 1998.

14 Research for International Tobacco Control. Bridging the research gaps in global tobacco control: report on the Ottawa meeting, November 4-6, 2002. Ottawa: Research for International Tobacco Control, 2002.

15 Samet J, Yach D, Taylor C, et al. Research for effective global tobacco control in the $21^{\text {st }}$ century: report of a working group convened during the $10^{\text {th }}$ World Conference on Tobacco or Health. Tobacco Control 1998;7:72-7.

16 Centers for Disease Control and Prevention, Global Youth Tobacco Survey, www.cdc.gov/tobacco/global/GYTS.htm, September 5, 2003.

17 Navas-Acien A, Peruga A, Breysse P, et al. Secondhand tobacco smoke in public places in Latin America, 2002-2003. JAMA 2004;291:2741-5.

18 Jaakkola MS, Ma J, Yang G-H, et al. Determinants of salivary cotinine concentrations in Chinese male smokers. Prev Med (in press).

19 Stillman FA, Samet JM, Wipfli HL, et al. A global tobacco research network. Paper presented at the 12th World Conference on Tobacco or Health. Helsinki, Finland: August 8, 2003.

20 John E Fogarty International Center, International Tobacco and Health Research and Capacity Building Program, http://www.fic.nih.gov/ programs/tobacco.html, September 5, 2003.

21 Research for International Tobacco Control. Bridging the research gaps in global tobacco control: a synthesis document. Ottawa: Research for International Tobacco Control, 2002.

22 Tobacco Control and EC Development Policy. Speaking note for Commissioner Nielson at the high level round table on tobacco control and development policy, Brussels, February 42003. 